\title{
Claves belgas para la lectura de Por la Europa católica de Emilia Pardo Bazán
}

\author{
Belgian keys to Read Por la Europa Católica \\ by Emilia Pardo Bazán
}

\author{
Lieve Behiels \\ KU Leuven, Thomas More
}

\section{RESUMEN}

En 1901, Emilia Pardo Bazán realizó un viaje a Bélgica para conocer desde dentro el catolicismo social belga. Nos preguntamos en este artículo si la autora entrevistó las figuras realmente relevantes, si se documentó en las fuentes importantes y si da una imagen fiable de la situación sociopolítica belga al lector español. En primer lugar ofrecemos datos sobre la publicación de los textos, luego esbozamos el contexto del papel social de la Iglesia en Bélgica y en España y analizamos los capítulos sobre política social de Por la Europa católica. Podemos concluir que la autora entrevistó figuras intelectuales de pro entre el clero y visitó obras sociales enmarcadas por la Iglesia, pero no contactó con la incipiente democracia cristiana. Sobre el socialismo se documenta en Le socialisme en Belgique de Destrée y Vandervelde, que sigue siendo una referencia histórica. Aunque estaba al tanto de las disensiones en el seno del partido católico y de la alta conflictividad social, en su ensayo tiende a presentar una imagen demasiado idílica de Bélgica, probablemente para no menoscabar la ejemplaridad de su catolicismo social para España.

Palabras Clave: Emilia Pardo Bazán, catolicismo social, socialismo, Bélgica, periodismo s. XIX, literatura de viajes.

\begin{abstract}
In 1901, Emilia Pardo Bazán took a trip to Belgium in order to familiarize herself with Belgian social Catholicism; the result was an essay, Por la Europa católica. In this article we will try to answer the following questions: did the author interview relevant personalities, did she document herself with trustworthy sources and did she provide a faithful image of the Belgian socio-political reality to her Spanish readers? First we will offer data about the publication of the texts, second we will sketch the context of the social role of the Church in Belgium and Spain at the turn of the century, and then we will analyse the chapters on social policy in the essay. We may conclude that Pardo Bazán interviewed Catholic figures of the highest level and visited important social works supervised by the Church, but she made no contact with the early Christian democracy. Her main source of information on the socialist movement is Le socialisme en Belgique, still a historical reference work. Although she knew about the tensions in the Catholic party and the huge social antagonisms, in her book she tends to present a too idyllic image of Belgium, probably in order to be able to present the country's social Catholicism as an example for Spain.
\end{abstract}

Key words: Emilia Pardo Bazán, Social Catholicism, Socialism, Belgium, 19th century Journalism, Travel literature. 
En el verano de 1901, Emilia Pardo Bazán emprendió un viaje que la llevó a Bélgica y Holanda. Su intención era conocer en profundidad y de primera mano el catolicismo belga en su vertiente social. Quería saber cómo un país europeo podía ser dirigido por un gobierno católico y ser al mismo tiempo un ejemplo de modernidad. Al mismo tiempo se proponía visitar los grandes tesoros artísticos de Bélgica y Holanda. El resultado de sus observaciones fue una serie de artículos, primero, y luego un libro de viajes, Por la Europa católica. A pesar del interés creciente por la obra periodística de la Pardo Bazán, hasta la fecha no existe ningún estudio en profundidad de Por la Europa católica ${ }^{1}$. Después de dar cuenta de las diferencias que existen entre los artículos y el volumen, en este trabajo nos proponemos repasar los contactos que tuvo y las lecturas que realizó doña Emilia en función de su objetivo: esbozar un panorama de la 'cuestión social' tal como se planteaba en Bélgica. Analizaremos si los contactos que tuvo eran representativos y si la imagen de la situación belga que proyecta al lector español tenía visos de objetividad. Por motivos de espacio, las consideraciones estéticas de la autora sobre los tesoros histórico-artísticos que va visitando caen fuera de este estudio.

\section{UNA SERIE DE ARTÍCULOS RECOGIDOS EN UN VOLUMEN}

La autora dio cuenta de sus impresiones en una serie de artículos publicados en Los lunes de El Imparcial en el otoño de $1901^{2}$. Fueron recogidos en el volumen titulado Por la Europa católica, publicado en 1902 como tomo XXVI de las Obras Completas ${ }^{3}$. Complementan este volumen tres breves apuntes, «Un sarao», «Un congreso» y «Por las bodegas» reunidos bajo el título de «Provincianos franceses» (pp. 649-660) y «En Lisboa»y «Tomar» que constituyen las «Notitas portuguesas» (pp. 661-667); estos textos quedan fuera del marco de este trabajo.

Haciendo abstracción de correcciones y modificaciones puntuales, se pue-

\footnotetext{
${ }^{1}$ Véase González Herrán, 1999 y 2000, Freire López, 1999 y 2005 y Jiménez Morales, 2008.

${ }^{2}$ Los artículos que conformarían el libro se publicaron los lunes 12, 19 y 26 de agosto, $2,9,16,23$ y 30 de septiembre, 7 y 21 de octubre, 18 de noviembre y 30 de diciembre de 1901. Cecilio Alonso (2007) hizo la lista de todas las contribuciones de la autora para Los lunes de El Imparcial entre 1883 y 1933. La autora había ideado la publicación periodística como una 'campaña' y estaba decepcionada porque habría preferido un ritmo de dos artículos por semana en el cuerpo del periódico. En una carta a Ortega Munilla escribió lo siguiente: «Es cierto que no convenimos nada, pero dada la índole de esos artículos, yo supuse que publicarían Vds. dos por semana en el cuerpo del periódico. La publicación en Los Lunes les quita interés, y esta campaña, que podría haber sido bonita, se ha desgraciado». Carta fechada en Mondariz, 31 de agosto de 1901, citada en Alonso (2007: 46).

${ }^{3}$ Fue impreso en Madrid, Tip. Moreno. Existe una edición reciente, Pardo Bazán, 2006b, a la que referiremos a continuación.
} 
den observar algunos cambios de mayor calado entre la serie de artículos sobre Bélgica y la publicación en volumen. El libro empieza por una «Advertencia al que leyere», evidentemente un texto redactado para abrir la nueva edición. La autora expone su doble propósito al emprender su viaje:

\begin{abstract}
El primer argumento es social. Yo me dirigía a Bélgica movida por el deseo de ver cómo funcionaba una nación donde los católicos ocupan el poder desde hace diecisiete años y donde, sin embargo, no se ha acentuado indiscretamente el espíritu conservador; una nación que figura entre las más adelantadas, y que es católica, al menos en gran parte, con un catolicismo activo, coherente, vivaz, sin letras muertas. El segundo argumento es artístico. (Pardo Bazán, 2006b: 589).
\end{abstract}

La autora afirma que sus impresiones artísticas habrían podido desembocar en un texto mucho más amplio que no llegó a escribir por falta de tiempo. Promete volver sobre el tema si en alguna ocasión puede repetir el viaje. Evoca las reacciones del público ante sus artículos que tratan de un asunto «que apenas se había tocado en la prensa» (589). Los lectores le mandaron noticias sobre instituciones y organismos sociales españoles que según ella siguen siendo 'islas' cuando lo que se necesita es un 'continente'. Distingue en la obra social católica un aspecto extrínseco, la defensa de la sociedad burguesa constituida, y otro intrínseco, que es lo que más le importa, «sus elementos civilizadores y moralizadores, la dignidad y belleza que traería a todas las relaciones de la vida española» (590). En conclusión, teme que en España no se emprenda a tiempo la obra social en la escala necesaria aunque infunde ánimos a los que «madruguen y se echen la azada al hombro» (590).

El primer capítulo del libro Por la Europa católica titulado «Desde el tren» no forma parte de la serie publicada en El Imparcial. Este capítulo contiene consideraciones sobre las incomodidades y los encantos de los viajes y lo poco aficionado que es el español a viajar y recuerda en este sentido un texto previo de la autora, «El viaje por España», publicado en La España Moderna en 1895 (véase González Herrán, 2000: 52). La autora destaca la importancia de los viajes para los eruditos y los artistas, para los cuales los viajes pueden significar una nueva orientación. La frase: «También acerca del estado social de una nación se aprende mucho viajando por ella», además de referir al tema del libro en su totalidad, en el nivel del capítulo constituye una transición hacia la crítica de la España contemporánea: si muchas ciudades han erigido teatros, todas tienen plaza de toros. Según la autora, la afición a los toros es incompatible con la sensibilidad estética. El último tercio del artículo se dedica a la descripción de una visita al pueblo de Sarria (provincia de Lugo). La autora fue invitada por los señores de Oñate a visitar las Escuelas Públicas, dirigidas por los padres mercedarios, donación de don Matías López, el padre de sus anfitriones, que fue fabricante de chocolates y mecenas. Describe con entusiasmo el edificio nuevo, lleno de luz y de aire, las instalaciones y dependencias, el abundante material escolar, y lo contrasta con la escuela 
antigua que le evoca una enseñanza indigna de tal nombre, la descrita por Galdós en El doctor Centeno, «alianza del tedio con la rebeldía» (Pardo Bazán, 2006b: 594). De este resumen se puede deducir que el texto no tiene nada que ver con Bélgica. La autora no menciona la fecha del viaje a Sarria, no sabemos si se produjo antes o después del viaje al norte de Europa. La razón de incluirlo se puede hallar tal vez en la «Advertencia al que leyere»: las Escuelas de Sarria constituyen una obra modélica que merecería reproducirse en España.

Otras diferencias entre la serie de artículos que salió en la prensa y el libro son el orden en que aparecen y la presencia/ausencia de una dedicatoria. En la tabla mencionamos la fecha de publicación en prensa de los artículos, el título, la persona a la que va dedicada el artículo, el número del capítulo correspondiente en Por la Europa católica y la persona a la que se dedica el capítulo.

Según escribe la autora en una carta a Giner de los Ríos, El Imparcial publicó sus textos en el orden equivocado, «[...] alterando su orden y barajándolos lastimosamente» (Varela, 2001: 491), sin más detalles. Podemos suponer que el orden que prefiere equivale al orden de los capítulos del libro.

El único artículo dedicado es el primero y la omisión de la dedicatoria en la versión de las Obras completas en el fondo no importa, puesto que toda la primera página del texto va dirigida al Conde de Romanones, Ministro de Educación y trata de la importancia de introducir en el espíritu de los españoles la civilización europea, tarea para la cual la autora se estima perfectamente calificada (Pardo Bazán, 2006b: 596). Se observa una correspondencia entre el tema tratado en los capítulos y la persona a la que va dedicada. «Desde el tren» se dedica a la señora de Oñate que hizo visitar a doña Emilia la escuela de Sarria. «Primer testimonio», que relata una discusión entre la autora y un sacerdote francés sobre las relaciones entre la Iglesia y el estado en Francia, va dirigido a Antolín López Peláez, sacerdote e investigador, hombre abierto a las ideas nuevas, futuro obispo de Jaca y arzobispo de Tarragona, que apoyó la candidatura de Galdós al premio Nobel. «El país de la pintura» va dedicado al pintor Aureliano de Beruete y «Gante. El Cordero Místico» al pintor Joaquín Sorolla, dos artistas de relieve, contemporáneos de la autora. «La abadía de Maredsus» se dedica a Boris de Tannenberg, hispanista francés, conocido de la autora con el que había visitado la sección de enseñanza de la Exposición Universal de París en $1900^{4}$. Ciriaco Sancha y Hervás fue nombrado arzobispo primado de Toledo en 1898; fundó congregaciones, asociaciones e instituciones religiosas y se preocupó por la asistencia a los más necesitados; la autora le dedica el capítulo «Trabajadores de la viña» en el que relata su entrevista con monseñor Mercier sobre el papel de los intelectuales

\footnotetext{
4 «Me acompañaba un profesor cultísimo, Boris de Tannenberg, bien conocido de los literatos españoles» (Pardo Bazán, 2006a: 501).
} 


\begin{tabular}{|c|c|c|c|c|}
\hline $\begin{array}{l}\text { Fecha de } \\
\text { publicación }\end{array}$ & Título del artículo & $\begin{array}{l}\text { Artículo } \\
\text { dedicado a }\end{array}$ & Capítulo & $\begin{array}{l}\text { Capítulo } \\
\text { dedicado a }\end{array}$ \\
\hline & [Desde el tren] & & 1 & $\begin{array}{l}\text { A la señora de } \\
\text { Oñate }\end{array}$ \\
\hline 12.08 .1901 & Hacia la frontera & $\begin{array}{l}\text { Al Ministro de } \\
\text { Educación } \\
\text { Pública }\end{array}$ & 2 & \\
\hline 19.08 .1901 & Primer testimonio & & 3 & $\begin{array}{l}\text { A D. Antolín } \\
\text { López Peláez }\end{array}$ \\
\hline 26.08 .1901 & El país de la pintura & & 4 & $\begin{array}{l}\text { A Aureliano } \\
\text { de Beruete }\end{array}$ \\
\hline 02.09 .1901 & La abadía de Maredsus & & 5 & $\begin{array}{l}\text { A Boris de } \\
\text { Tannenberg }\end{array}$ \\
\hline 09.09 .1901 & Un obispo & & 6 & $\begin{array}{l}\text { Al Padre } \\
\text { Castellanos }\end{array}$ \\
\hline 16.09 .1901 & $\begin{array}{l}\text { Amberes. Un museo } \\
\text { católico. Una procesión }\end{array}$ & & 7 & $\begin{array}{l}\text { A Elena } \\
\text { Español }\end{array}$ \\
\hline 23.09. 1901 & Trabajadores de la viña & & 9 & $\begin{array}{l}\text { Al cardenal } \\
\text { Sancha }\end{array}$ \\
\hline 30.09 .1901 & $\begin{array}{l}\text { Más trabajadores. La } \\
\text { Gilde }\end{array}$ & & 10 & $\begin{array}{l}\text { A D. Luis } \\
\text { Chaves }\end{array}$ \\
\hline 07.10 .1901 & $\begin{array}{l}\text { Reposo en el pasado. El } \\
\text { Museo Plantino }\end{array}$ & & 8 & $\begin{array}{l}\text { Al barón de la } \\
\text { Vega de Hoz }\end{array}$ \\
\hline 21.10 .1901 & Gante. Relámpago rojo & & 11 & $\begin{array}{l}\text { A Sanz } \\
\text { Escartín }\end{array}$ \\
\hline 18.11 .1901 & $\begin{array}{l}\text { Gante. El cordero } \\
\text { místico }\end{array}$ & & 13 & $\begin{array}{l}\text { A Joaquín } \\
\text { Sorolla }\end{array}$ \\
\hline 30.11 .1901 & El descanso dominical & & 12 & $\begin{array}{l}\text { A D. Antonio } \\
\text { Maura }\end{array}$ \\
\hline
\end{tabular}

TABLA 1.-Dedicatorias en los artículos de El Imparcial y en los capítulos de Por la Europa católica. 
católicos. «Más trabajadores. La Gilde», el artículo sobre la Liga de aldeanos de Lovaina, se dedica a Luis Chávez, que había fundado en la zona de Zamora unas cajas rurales y es mencionado en la «Advertencia al que leyere» (p. 589). «Gante. Relámpago rojo», sobre el movimiento corporativo y el partido socialista, va dedicado a Eduardo Sanz y Escarpín, político y sociólogo, autor de varios libros sobre reformas sociales. El motivo por el que la autora le dedica el capítulo sobre su visita al Museo Plantyn-Moretus de Amberes a Enrique Leguina y Vidal, barón de la Vega de Hoz, senador por la Sociedad Económica de Sevilla en la legislatura 1901-1902, no queda claro a primera vista. El capítulo sobre el «Descanso dominical» fue dedicado a Antonio Maura, en 1902 ministro de Gobernación, Académico de la Española y corresponsal de doña Emilia ${ }^{5}$. Podemos observar, pues, una relación entre el contenido de los capítulos y la relevancia social de las personas a las que quedan dedicados.

Antes de ocuparnos de la imagen de Bélgica que la autora proyecta a través de sus artículos, conviene esbozar la situación del catolicismo social en España con la cual quiere comparar lo que va a encontrar en Bélgica y repasar brevemente unos datos sobre la situación sociopolítica y religiosa en este último país en el cambio de siglo. Este esbozo permitirá a continuación evaluar las referencias que hace la autora a estas facetas del panorama belga.

\section{EL CATOLICISMO SOCIAL EN ESPAÑA}

En los dos países se puede observar un antes y un después de la encíclica Rerum Novarum del papa León XIII, publicada en 1891. Este documento dio un gran impulso al catolicismo social en toda Europa (Montero, 2004: 398). La diferencia entre España y otros países consiste en un «desfase cronológico» ${ }^{6}$. Antes de la encíclica, en España, la discusión y las iniciativas en cuanto a política social eran minoritarias en círculos católicos, por lo cual Rerum Novarum era un mensaje nuevo que aún tenía que penetrar en las conciencias. Por lo que se refiere al modelo asociativo para los obreros, Feliciano Montero destaca que

[...] mientras en España el Círculo Católico y el 'gremio' seguían siendo proclamados como el ideal asociativo, durante la década posterior a Rerum Novarum,

${ }^{5}$ Doña Emilia le había anunciado su viaje al norte de Europa, calificando Bélgica como un país «adelantado, católico y feliz» (Simón Palmer, 2008: 626).

${ }^{6}$ Montero, 2004: 398. Manuel Revuelta González (2000: 102) también pone de relieve este desfase, para el cual alega varios motivos: «Este retraso se explica por la lentitud del desarrollo industrial del país y porque las preocupaciones fundamentales de los católicos se centraban más en la conservación de la unidad religiosa con los privilegios del estado confesional y en el freno al laicismo mediante la enseñanza y la propaganda». 
en otras latitudes el debate giraba en torno al sindicato puro y profesional. (Montero 2004: 398-399).

Manuel Revuelta González fecha en 1899 la llegada a España de las nuevas orientaciones demócrata-cristianas que abandonan el paternalismo y defienden la organización de los obreros desde abajo, en agrupaciones donde asumieran el protagonismo. En las asociaciones sociales del catolicismo europeo, el modelo imperante tendía a la armonía entre ricos y pobres e incorporaba en las actividades de beneficencia la instrucción moral y religiosa; el orden establecido, liberal y capitalista, no se cuestionaba (Revuelta González, 2000: 102-103). Se trataba de evitar que las clases populares cayesen en las garras de los socialistas, designados explícitamente como el enemigo a combatir en el texto de la encíclica de $1891^{7}$.

El punto de partida de Emilia Pardo Bazán es la insuficiencia de las obras sociales de inspiración católica existentes en España y es posible que la información de la que disponía la autora al propósito fuera incompleta. Así lo reconoce ella misma en la «Advertencia al que leyere» que encabeza la publicación en volumen de sus artículos, aludiendo a las cartas que recibió cuando sus textos salieron en El Imparcial: «en algunos se me comunicaban noticias respecto de instituciones y organismos existentes en España» (Pardo Bazán, 2006b: 589). Además, advierte el clima de violencia del que es víctima el clero y que puede atribuirse a su falta de compromiso con los problemas sociales ${ }^{8}$.

El contexto más amplio en el que hay que situar no solo el relato del viaje a Bélgica sino también otras publicaciones y discursos de la autora en el cambio de siglo es el regeneracionismo. Marisa Sotelo apunta dos claves para situar el pensamiento regeneracionista de la autora:

de un lado, [...] la regeneración por la cultura y la educación, y de otro, [...] la necesaria apertura a las corrientes del pensamiento europeo, que en el caso de doña Emilia se produce desde una actitud manifiestamente ecléctica, importando lo más fecundo de la cultura europea, francesa singularmente, sin renunciar nunca a la tradición nacional. (2005: 358).

La autora sitúa explícitamente su ensayo dentro de esta apertura a Europa y declara: «Sintiéndome tan acérrima española, cada vez propendo más a

\footnotetext{
${ }^{7}$ Véase la traducción de la encíclica en la página web del Vaticano: Carta encíclica Rerum novarum del Sumo Pontífice León XIII sobre la situación de los obreros, [http:// www.vatican.va/holy_father/leo_xiii/encyclicals/documents/hf_l-xiii_enc_15051891_rerumnovarum_sp.html, consultado el 10.08.2010].

${ }^{8}$ Pilar Faus Sevilla observa que doña Emilia «[...] acertadamente vislumbra la existencia de un problema más grave, y especialmente causante de la violencia de la que es víctima el estamento religioso. Se trata de su miopía e indiferencia ante los graves problemas que afectan a las clases bajas de la sociedad moderna y ante los cuales solamente el socialismo realiza una importante labor». (2003, vol. II: 198)
} 
buscar fuera de España remedios y lecciones» (Pardo Bazán, 2006b: 596). Para el tema que le interesa, «la bien o mal llamada cuestión religiosa» (596), quiere conocer lo que ocurre en Francia y en Bélgica:

[...] una república donde domina el laicismo, una monarquía donde domina el catolicismo desde hace diez y siete años - y ambas, la república y la monarquía, como ya quisiéramos estar nosotros de adelantadas y prósperas; lo cual, a esta distancia, parece significar que de todos modos se puede ser europeo, y que los males de España no deben achacarse al catolicismo, sino a la manera que tuvimos siempre de entender y practicar esta religión de paz y dulzura. (597).

En el ensayo, la autora no llegará a entrar detenidamente en el caso francés; se limita a referir una conversación mantenida en el tren con un cura de Burdeos que le explica el modus vivendi pacífico entre el clero y el gobierno francés que le parece envidiable ${ }^{9}$.

Marisa Sotelo concluye su estudio sobre el regeneracionismo de doña Emilia afirmando que es esencialmente moral y cultural (2005: 367). Esto puede explicar por qué no encontramos en sus artículos referencias a instituciones oficiales belgas o españolas o a iniciativas legales tendentes a mejorar la suerte de los necesitados. En Bélgica, las primeras leyes sociales surgieron a partir de 1887 en respuesta directa a las revueltas obreras del año anterior ${ }^{10}$, en España más tarde aún: las primeras leyes laborales, entre las que figura la ley de protección del trabajo de la mujer e infantil data de 1900, bajo el gobierno conservador de Eduardo Dato ${ }^{11}$. En Bélgica le interesan las iniciativas no gubernamentales, las católicas y las socialistas.

\section{EsBozo DE LA SITUACIÓN SOCIOPOLÍTICA EN BÉLGICA HACIA EL CAMBIO DE SIGLO}

Recuerdo la «Advertencia al que leyere» que precede el volumen titulado Por la Europa católica: «Yo me dirigí a Bélgica movida por el deseo de ver cómo funcionaba una nación donde los católicos ocupan el poder desde hace diecisiete años y donde, sin embargo, no se ha acentuado indiscretamente el espíritu conservador» (Pardo Bazán, 2006b: 589). Efectivamente, el 10 de junio de 1884 el partido católico obtiene la mayoría absoluta de los escaños en

${ }^{9}$ «—_Pero no sería mejor —objeté [al cura que espera que los españoles tengan muy pronto una guerra épica]_ que allá penetrase ese bendito 'espíritu nuevo', la calma, la transigencia, o al menos la lucha cortés en el terreno de la inteligencia, de la educación y de las buenas obras?»(Pardo Bazán, 2006b: 602)

${ }^{10}$ Véase la lista en Mabille, 1986: 187-188.

11 A partir de entonces, tanto los conservadores como los liberales se dedican a sacar adelante nuevas leyes e instituciones como el Instituto de Reformas sociales (1904) y el Instituto Nacional de Previsión (1908), véase Montero 1997. 
el parlamento y la conserva hasta 1917 (Mabille, 1986: 183). La explicación de la derrota de los liberales se encuentra en la política anticlerical militante del gobierno Frère Orban-Van Humbeeck, la división interna de los liberales en una corriente conservadora (llamada 'doctrinaria') y otra radical y progresista, la combatividad católica contra la política educativa laicizante y el temor al socialismo pujante.

Tratamos con algún detalle el aspecto de la legislación electoral porque en las conversaciones de doña Emilia con sus interlocutores belgas, este tema vuelve una y otra vez. No hay que subestimar la importancia de la aritmética electoral: debido al sistema mayoritario, en las elecciones de 1884 bastó un aumento de menos del $10 \%$ de votos católicos para cambiar radicalmente la composición del parlamento (Mabille, 1986: 194). Eran los años del sufragio restringido: solo podían votar un ínfimo número de ciudadanos masculinos que figuraban en la lista de grandes contribuyentes, más, a partir de 1883, para las elecciones locales, los llamados 'capacitados', hombres con título superior o que ejercían profesiones de responsabilidad.

La mayoría católica se veía enfrentada con una fuerte oposición ideológica por parte de los librepensadores (liberales y socialistas) en el marco de la lucha por el control de la educación, uno de los temas dominantes de la política belga hasta pasada la segunda mitad del siglo XX. Además, los liberales sociales y los socialistas exigían reformas sociales. De ahí que el gobierno católico no podía «acentuar indiscretamente el espíritu conservador».

El 5 de abril de 1885 se creó el partido obrero belga (Parti Ouvrier Belge, Belgische Werkliedenpartij) que ganó adhesiones masivas a partir de la represión sangrienta de las revueltas de 1886. El partido pretendía participar en el poder por la vía parlamentaria y en consecuencia, el sufragio universal va a figurar en un lugar prominente en su programa. Se organizaron varias manifestaciones nacionales masivas entre 1886 y 1893 para sensibilizar a la población. Hubo huelgas generales para exigir el sufragio universal en 1891, 1893, 1902 y 1913 a las que los poderes establecidos reaccionaron con una mezcla de represión y adaptaciones del sistema electoral (Deneckere, 2005: 519). En 1893 la dirección del partido socialista decidió terminar la huelga general en el momento en que el parlamento aprobó el sufragio universal plural. Al mismo tiempo se introdujo el voto obligatorio. El resultado fue que el número de electores se multiplicó casi por diez ${ }^{12}$. En 1894 se organizaron por

${ }^{12}$ En el sistema plural, todos los hombres mayores de 25 años tenían un voto, pero algunos, dos o más. Los casados o viudos con descendientes legítimos que pagaban al año cinco francos de impuestos sobre la vivienda tenían derecho a un voto suplementario, asî como los propietarios de edificios con un valor mínimo de dos mil francos o los detentores de una libreta de la caja general de ahorros que rentaba al año un mínimo de cien francos. Los padres de familia-propietarios y los detentores de un título de la enseñanza secundaria superior y los que ejercían una profesión que implicaba esta capacidad recibían dos votos suplementarios. Nadie tenía más de tres votos. El número de votos aumentó de golpe de 
primera vez elecciones basadas en la nueva ley electoral y los socialistas hicieron su entrada en el parlamento. El gobierno de Smet de Naeyer se propuso sustituir el sistema mayoritario por un sistema de representación proporcional para que los electores de la minoría también pudieran decidir sobre la composición de los cuerpos representativos. El 24 de noviembre de 1899 el parlamento aprobó la proposición de ley y después de las primeras elecciones bajo el sistema de la representación proporcional, los católicos perdieron escaños mientras que los liberales y, en menor medida, los socialistas, aumentaron su presencia en la cámara de los diputados. Cuando doña Emilia visitó Bélgica, había en el parlamento 86 diputados católicos, 33 liberales y 33 socialistas (Mabille, 1986: 195). Como el sufragio universal plural y la representación proporcional no habían producido el avance electoral deseado, a partir de 1900 los socialistas volvieron a hacer campaña por el sufragio universal.

Esta pujanza del movimiento socialista explica las iniciativas tomadas en el campo católico para atraer al mundo obrero. Existía la conciencia, agudizada después de la publicación de Rerum novarum, de que había que ir más allá de la caridad paternalista, de la limosna y de la escuela dominical a fin de mejorar la vida material del obrero y del campesino. Se invirtió gran energía en la creación de estructuras intermedias entre el individuo y el estado. El ideal de los prohombres del catolicismo social como Joris Helleputte y Arthur Verhaegen era una sociedad corporativista y estamental cuya elaboración ideológica se haría en la universidad católica de Lovaina. Se trataba de ofrecer a la sociedad una alternativa a los excesos del capitalismo industrial y a la amenaza del socialismo colectivista (De Maeyer y Van Molle, 1998: 76). Helleputte es el fundador de la 'Gilde van Ambachten en Neringen' de Lovaina (1885) que figura como eje de una serie de iniciativas sobre las que volveremos cuando nos ocupemos del texto de Emilia Pardo Bazán. Sin embargo, en los primeros años del siglo XX, este modelo ya no podía ofrecer una respuesta con visos de futuro a la cuestión social. Tuvo que dar paso al sindicalismo católico (De Maeyer y Van Molle, 1998: 109). Pero mientras Helleputte nunca abandonó el corporativismo, su correligionario Arthur Verhaegen, llamado 'el barón rojo', fue más allá y fundó en Gante en 1890 el primer sindicato católico, el 'Antisocialistische Werkliedenbond' ('Sindicato Obrero Antisocialista') y lanzó al año siguiente el periódico Het Volk ('El Pueblo') que sería durante décadas el órgano del movimiento obrero cristiano en Flandes. Estaba a favor de la autonomía relativa de los demócratas cristianos en el marco del partido católico (De Maeyer, 1994: 209 y Mabille, 1986: 206). Estos partidarios de profundas reformas sociales constituían una mino-

136.755 a 1.370.687: el cuerpo electoral se componía en aquellas fechas grosso modo de 850.000 hombres con un voto, 290.000 con dos en 220.000 con tres votos. Véase Deneckere, 2005: 539 y Mabille, 1986: 193. 
ría activa en el seno del partido católico y consiguieron hacer aceptar sus propuestas apelando a la amenaza del fantasma socialista. He aquí a grandes rasgos el panorama con el que se va a encontrar la autora en su viaje de 1901.

\section{Los contactos de Emilia PaRdo BAZÁn en El MUNDO CATÓlico Belga}

En el verano de 1901, doña Emilia mantiene entrevistas en la abadía benedictina de Maredsous, con el obispo de Lieja, monseñor Doutreloux, con el fundador del Instituto de Filosofía de la Universidad Católica de Lovaina, el futuro cardenal Joseph Mercier y visita las instalaciones de la 'Gilde van Ambachten en Neringen' de Lovaina.

Llega a Maredsous con una carta de presentación de un «escritor católico» (Pardo Bazán, 2006b: 607) no identificado. No se trata de un monasterio cualquiera. Su fundación se sitúa en el contexto de la refundación de la orden benedictina a partir de la abadía de Beuron en Alemania. La abadía se consideraba como uno de los puntos de partida de la recristianización del país gracias a la alta reputación intelectual de la orden. Fue financiada por los industriales católicos ultramontanos más significados de Bélgica, entre otros Henri y Jules Desclée de Tournai y Joseph de Hemptinne de Gante, cuyo hijo Félix sería luego abad de Maredsous. Sucesivamente se erigieron la abadía (1873-1876), la iglesia abacial (1877-1881), las dependencias, un instituto y una escuela de arte. El arquitecto del conjunto, Jean-Baptiste Bethune, era un defensor militante del estilo neogótico (De Maeyer, 1994: 112). Félix de Hemptinne (1849-1913) ${ }^{13}$, en religión Dom Hildebrand, se hizo benedictino en Beuron en 1870 después de haber combatido en las filas de los zuavos del papa a los dieciséis años. Estuvo entre los monjes fundadores de Maredsous y fue elegido abad en 1890. En 1893, el papa lo nombró primado de la orden y le encargó el gobierno de Sant'Anselmo, el centro de estudios teológicos de la orden, su residencia casi permanente, de modo que doña Emilia no pudo encontrarse con él. Maredsous es, pues, un baluarte del ultramontanismo intelectual. A primera vista, no es el lugar más adecuado para informarse sobre las iniciativas más pujantes del catolicismo social.

La autora queda favorablemente impresionada por el clima de armonía y civilización que observa alrededor de la abadía: no hay taberna a tres pasos del edificio, no abundan los mendigos, no son solo las mujeres las que practican el culto sino también los hombres, no hay grosería sino buena educación. Le llama la atención sobre todo el tono culto y matizado del discurso proferido por los dos benedictinos a los que entrevista y les pregunta si existen en Bélgica las polémicas al uso «dentro del catolicismo profesional» (Pardo Bazán, 2006b: 609) español. Los benedictinos le responden: «Nunca con in-

\footnotetext{
${ }^{13}$ Para los datos biográficos, véase Schmitz, 1962.
} 
jurias, calumnias ni personalidades. Sólo hace algunos años empeñaron acalorada discusión sobre ideas los demócratas y los conservadores católicos. Se debatía una ley. Ya votada, acordaron acatarla unánimemente» (609). Aunque no se proporcionen más detalles al respecto, es probable que se trate de la ya mencionada ley sobre la representación proporcional de 1899, cuando el ala conservadora del partido católico votó en contra (Mabille, 1886: 195). La declaración de los benedictinos es cierta en el sentido de que la unidad de las fuerzas católicas siempre prevaleció sobre las contradicciones internas, lo cual implicaba que la democracia cristiana se hallaba oprimida en un marco elaborado por las elites tradicionales y eclesiásticas (Deneckere, 2005: 550). Los monjes explican las iniciativas legislativas favorables al proletariado en el marco de la competencia con el socialismo:

A él [i.e. al partido democrático católico] deben los proletarios el derecho al voto y un sinnúmero de mejoras y reformas que los católicos se apresuran a establecer antes que las establezcan los socialistas enemigos del catolicismo. El error de los católicos fue la tendencia nimiamente conservadora en las cuestiones políticas y sociales. (Pardo Bazán, 2006b: 609).

El adverbio es más que significativo. Cuando la autora menciona a Émile Vandervelde, para su gran sorpresa, los benedictinos expresan su estima por la convicción del líder socialista.

De Maredsous, Emilia Pardo Bazán se dirige a Lieja donde la recibe monseñor Victor-Joseph Doutreloux (1837-1901), obispo de la diócesis a partir de 1879. Creó la Escuela de Lieja, un foco de pensamiento y de acción sociales a finales del siglo XIX. Presidió tres congresos internacionales en 1886, 1887 y 1890 y constituyó un Comité social católico que reunió a altos personajes del mundo católico internacional. El 14 de enero de 1894, monseñor Doutreloux publicó su Lettre pastorale sur la question ouvrière ('Carta pastoral sobre la cuestión obrera'), prologada por el propio León XIII, que fue considerada como el comentario autorizado de la encíclica Rerum Novarum (1891, véase Gérin, 1978: 92). El discurso relatado por Emilia Pardo Bazán recoge las líneas maestras de esta carta pastoral: se trata de mejorar la vida moral y material del proletario y el mundo asociativo desempeña un papel esencial en ello. Mientras que Doutreloux estaba claramente a favor de la justicia social y de la democracia política, al mismo tiempo seguía defendiendo los principios de base del corporativismo, de modo que hay que matizar su progresismo (Aubert, 1994b: 173 y Deneckere, 2005: 601). Aquí también se describe la acción social católica como una táctica defensiva: «No conocemos otro medio de atajar los progresos del socialismo», le dice el obispo a doña Emilia (Pardo Bazán, 2006b: 612). Monseñor Doutreloux reconoce el desacuerdo de los católicos conservadores que

[...] no por mala intención, por error, suponían que acaso hubiese exageración en el cuadro, o que los resultados de nuestro espíritu democrático serían peores que 
el daño que tratábamos de remediar. Hoy se me figura que van convenciéndose y que caminamos a la unidad de fines (612).

Esta convergencia de opiniones en el campo católico no se realizó realmente. A partir de 1890 se había producido una ruptura puesto que para los grandes industriales católicos, como los ya mencionados Desclée y de Hemptinne, iban demasiado lejos las correcciones sociales que fueron propuestas en los congresos de Lieja y que había que realizar por vía legal (De Mayer 1994: 570). Al final de su episcopado, estas reticencias le provocaron cierto desánimo a monseñor Doutreloux (Simon, 1953: 347). En la entrevista, el obispo se presenta como «economista cristiano»(Pardo Bazán, 2006b: 612) y hace hincapié en lo conseguido en la clase campesina: las asociaciones agrícolas dirigidas por los sacerdotes de la diócesis, el banco agrícola, las cooperativas y mutualidades, la lucha contra el alcoholismo. La autora le hace tres preguntas concretas, la primera tan marcada por el contexto español que su interlocutor no la entiende:

- Monseñor dice que cada párroco, para organizar la cooperación a favor de los agricultores, busca en la parroquia un laico de capacidad. Ese laico, ¿es lo que allá llamamos 'el cacique', o sea la persona a quien el Gobierno presta influencia a cambio de servicios electorales?

Y el Obispo, extrañado, me contestó:

- Aquí no sabemos qué es eso. No comprendo a qué clase de personas alude usted (Pardo Bazán, 2006b: 614).

La segunda pregunta trata de quiénes son los beneficiarios de las obras sociales. La respuesta del obispo es matizada: por un lado, un criterio amplio, por otro, una neta separación entre el campo católico y el enemigo ${ }^{14}$. La última pregunta de la autora atañe al carácter de la caridad cristiana:

- Encarece Monseñor, y encarecen aquí en general los católicos, la conveniencia de respetar la dignidad del obrero, de no dar a los beneficios carácter de limosna. ¿Es que se ha transformado la caridad cristiana, rompiendo los moldes de la Edad Media? (614).

La respuesta del obispo demuestra hasta qué punto sigue pensando y actuando dentro del molde más tradicional, a pesar de su compromiso social:

— ¡Ah! —murmuró. — Lo más hermoso de la Edad Media no lo hemos desechado. ¡ $\mathrm{Si}$ viese usted este año a las señoras de la Asociación para enfermos, lavando con sus manos unas úlceras cuyo aspecto me impidió comer aquel día, se acordaría usted de Santa Isabel y de San Francisco! (614).

${ }^{14}$ En su carta pastoral se expresa en términos más radicales: «Un autre principe de prudence chrétienne [...], c'est d'observer vis-à-vis des ennemis de Dieu, de la Religion et de la Société le «Ne ave eis dixeritis» de St Jean: pas de compromission, pas d'alliance avec les socialistes: s'ils poursuivent certains biens légitimes, ce n'est certes pas pour nous une raison de nous abstenir de les poursuivre aussi; mais laissons-les agir de leur côté et agissons du nôtre». (Doutreloux, 1894: 26) 
A los pocos días de esta visita, el sábado 24 de agosto de 1901, falleció el obispo, como lo recuerda la autora en una nota a su artículo. (615)

La tercera etapa del viaje de descubrimiento del catolicismo belga que emprende Emilia Pardo Bazán la conduce a Lovaina, adonde la llevan dos aspectos de la cuestión:

Dos instituciones me importan: la Universidad Católica y la 'Gilde' o Sociedad cooperativa. [...] La 'Gilde' me presentaría prácticamente la función social, y la Universidad la función docente [...] Son los dos aspectos del catolicismo belga: el pensamiento y la acción, la ciencia y la caridad. (627).

Primero se dirige a la universidad, más exactamente al Instituto Superior de Filosofía, donde tiene cita con el fundador, Désiré-Joseph Mercier (18511926). Lo encontró en Maredsous haciendo un retiro espiritual y allí concertaron el encuentro en Lovaina. Del capítulo que le dedica nuestra autora se podría deducir que el Instituto Superior de Filosofía formaba parte integrante de la Universidad, aunque en realidad se trataba de una institución relativamente autónoma, que no caía bajo el gobierno de la facultad de teología. El núcleo del Instituto fue una cátedra de filosofía tomista erigida en la universidad a petición de León XIII y confiada a Mercier en 1882 (Courtois, 1994: 80). Éste quería dar mayor amplitud a la iniciativa y en 1889 consiguió su objetivo: un instituto de estudios científicos y filosóficos superiores, donde se reconstruiría el edificio tomista conforme a los desarrollos intelectuales contemporáneos, pero en total independencia de la teología. En 1892 obtuvo del papa el permiso de fundar el seminario León XIII para asegurar una base filosófica a los futuros sacerdotes (Courtois, 1994: 80). Durante todo este proceso, Mercier tuvo que vencer las reticencias de las autoridades académicas de la universidad y las de parte del obispado pero en 1901 su autoridad estaba sólidamente asentada ${ }^{15}$. En la síntesis que presenta doña Emilia de su conversación con el prelado, alude en primer lugar al intercambio de ideas que tuvieron ambos acerca de la situación religiosa de España, al parecer fuertemente criticada por Mercier que la conocía de primera mano, aunque el lector no reciba ningún detalle al respecto ${ }^{16}$. La autora observa que «en la renovación de los estudios filosóficos en el sentido señalado por Santo Tomás de Aquino [...] coinciden todos los Institutos de enseñanza católica». Sin embargo, comprueba que el Instituto de Lovaina «no es el tomismo, según se entiende por allá» (Pardo Bazán, 2006b: 628), lo cual queda probado por la presencia de laboratorios de psicofísica y psicología experimental, ciencias que entusiasmaban a Mercier, que en 1887 había pasado un mes en el laboratorio

\footnotetext{
${ }^{15}$ Véase Aubert 1994a para más detalles acerca de la creación del Instituto.

16 «No sé si me resolveré por fin a comunicar al público las observaciones españolas y las iniciativas, españolas también, del desinteresado viajero; ahora sólo voy a explicar lo que caracteriza a la Universidad católica de Lovaina», dice la autora (Pardo Bazán, 2006b: 628).
} 
de Charcot en París (Aubert, 1994a: 104). Relaciona el espíritu científico que se respira en los laboratorios de Lovaina con el de los establecimientos científicos más importantes de España y menciona a Ramón y Cajal.

En las frases de Mercier que doña Emilia reproduce en estilo directo resuenan los textos programáticos de éste: «El error es a veces camino para la verdad, y el alma de verdad que encierra cada doctrina irradia al través de los errores» (Pardo Bazán, 2006b: 629), lo cual evoca la famosa frase «l'erreur peut être la devancière et est fréquemment la compagne de la vérité et [...] pour arracher une parcelle de vérité à l'inconnu, l'esprit humain doit souvent passer de longs et pénibles sentiers où il semble à première vue qu'il s'égare» ${ }^{17}$. Mercier quería que los jóvenes católicos cultivaran la ciencia por ella misma y se basaran en las metodologías más exigentes a fin de ser considerados interlocutores válidos en sus disciplinas. La entrevista pasa de las ciencias experimentales a las sociales. En este campo el hecho incontrovertible es el auge del socialismo. Según Mercier, «El socialismo se organiza donde quiera: es un 'hecho' gigantesco, el 'hecho' por excelencia de nuestra edad» (630). Para responder a este hecho, propone una concepción más comprensiva de las sociologías positivistas y de la sociología cristiana. Ante la conclusión del prelado de que «La Iglesia belga asume una gran responsabilidad... Lo sabemos. ¡Somos responsables!» (630), la autora se estremece. Teniendo en cuenta la estructura dicotómica que subyace al libro, en el que la autora establece comparaciones sistemáticas entre lo que sabe de España y lo que aprende en Bélgica, su conclusión acerca de la falta de responsabilidad de la iglesia española no podía ser más que desalentadora.

Es el mismo Mercier quien deposita a nuestra autora en la puerta de la Gilde, entidad cuyo nombre neerlandés no traduce, a lo mejor porque los equivalentes españoles más inmediatos, 'cofradía' o 'hermandad', no evocarían en el lector coetáneo las asociaciones adecuadas. La palabra designaba en la Edad Media una asociación de asistencia mutua, primero de tipo religioso, luego de tipo profesional, la unión de los que ejercían el mismo oficio. El nombre completo de la organización, 'Gilde van ambachten en neringen', podría traducirse como 'Gremio de artesanías y pequeñas industrias'. Más adelante en el texto, la autora utiliza para designar las 'gilden' la acertada expresión «asociaciones de compañerismo» (632). El nombre por sí solo ya es significativo del espíritu de la organización, fundada por Joris Helleputte en 1885. Helleputte era un arquitecto que trabajaba en el estilo neogótico y había diseñado los edificios del Instituto Superior de Filosofía y del seminario León XIII. En la visión del fundador había que preservar los grupos sociales no corrompidos por la modernidad: los agricultores y los artesanos. Para dignificar al trabajador manual y sacarlo de las garras de la industrialización

${ }^{17}$ Cita del informe de Mercier al congreso católico de Malinas, reproducido por Aubert (1994a: 112). 
salvaje, había que inspirarse de la organización laboral medieval. Dentro de esta visión corporativista y tradicionalista también encajaba la simpatía por los usos y costumbres populares y por la lengua del pueblo, de ahí que Helleputte fuera un gran defensor del movimiento flamenco. Las relaciones sociales desarrolladas orgánicamente tenían que ser preservadas (De Maeyer y Van Molle, 1998:78). Las iniciativas desplegadas por la Gilde eran numerosas y comprendían todo el espectro que iba desde la formación profesional a los servicios sociales y el ocio $^{18}$. Hasta las actividades de tiempo libre estaban indisolublemente unidas a la práctica de la religión ${ }^{19}$. Mientras que las actividades de la Gilde funcionaban dentro del ámbito reducido de sus miembros pero no conseguían atraer a las masas obreras, las asociaciones campesinas iban a obtener un éxito masivo. En 1890 Helleputte fundó el Boerenbond (Liga de campesinos), también con sede en Lovaina, una superestructura de asociaciones parroquiales, con tanto éxito que sigue siendo la asociación por excelencia de defensa de los intereses de los agricultores, hasta hoy en día. Doña Emilia aplica el término 'gilde' tanto a las asociaciones de artesanos como a las de campesinos.

La autora empieza poniendo de relieve el alto interés que le inspira esta organización: es uno «de esos focos de vida moral, cuyo descubrimiento es el encanto de mi viaje, y cuya existencia es honor de Bélgica y de su militante y civilizador catolicismo» (Pardo Bazán, 2006b: 631). La describe como un «fagocito social; el microbio salutífero o conservador que lucha con los microbios destructores de la sociedad tal cual hoy se encuentra constituida» (631). Se retoma el razonamiento ya familiar: como en los centros industriales los socialistas se aprovecharon del desinterés del mundo católico, los católicos se han volcado hacia las zonas agrícolas y han elaborado allí una red asociativa fuerte. Doña Emilia se extasía ante las numerosas iniciativas para fomentar el ahorro, incluso en las escuelas donde los alumnos tienen libretas de ahorro en los que van pegando sellitos (632). Hace hincapié en las iniciativas de formación profesional de los agricultores mediante conferencias y

${ }^{18}$ En 1886 se creó una caja para asistir a las viudas y los huérfanos, en 1889 una caja de previsión, en 1893 una caja para los miembros que perdían su empleo en invierno. En 1887 empezó la venta de pan barato, en 1888 la de medicinas a precio reducido. En 1888 se creó una sociedad para la vivienda de la clase trabajadora, en 1891 una bolsa de trabajo para que los parados pudiesen encontrar colocación. A fin de defender los intereses financieros de los miembros, la Gilde empezó en 1889 con un banco popular (De Maeyer y Van Molle, 1998: 107).

${ }^{19} \mathrm{El}$ único documento conservado de la 'Gilde' en el período que corresponde a la visita de doña Emilia es el libro de actas de las reuniones del gremio de los carpinteros. Se menciona una excursión a Amberes el 18 de agosto de 1901: por la mañana los participantes asistieron a la gran procesión de Nuestra Señora - la misma que la autora describe en el capítulo «Amberes. Un museo católico. Una procesión» (Pardo Bazán, 2006b: 619620)—, por la tarde visitaron el zoológico y las obras de la estación. Véase Gilde der Ambachten en Neeringen van Loven. Ambacht der Houtbewerkers, s.d.: f. 77. 
revistas que redundan en una mejora de la producción, en la asistencia de la Liga a la hora de venderla y en la consecuente mejora de los ingresos de los campesinos aunque la conclusión a la que llegue peque de optimismo: «[...] no sorprenderá que las clases agrícolas —aun en las propias Ardenas de Flandes, lo más atrasado y pobre de Bélgica- disfruten de un bienestar satisfactorio» (633). El papel de los párrocos es fundamental en todas estas iniciativas, como ya había sido destacado en la conversación con monseñor Doutreloux.

Al final del capítulo, la autora proporciona datos estadísticos sobre la Liga que saca, no de publicaciones internas de la organización, sino de un libro de dos autores socialistas al que recurre una y otra vez a partir de este capítulo: se trata de Le socialisme en Belgique (1898) de Jules Destrée y Émile Vandervelde, que sigue siendo una obra de referencia histórica sobre el tema. El dato de que «la manteca que actualmente se elabora es muy superior a la que se elaboraba hace un cuarto de siglo» (633) proviene de este ensayo, aunque no se mencione la fuente ${ }^{20}$. La conclusión del capítulo remite también a este libro. La autora observa que Vandervelde no puede sino reconocer que la penetración del socialismo en el mundo rural es reducida y que allí las cooperativas católicas le cortan el acceso. Y termina con otra cita de Le socialisme en Belgique: «Las corporaciones cristianas vacunan al aldeano contra el socialismo, inoculándole un poco de virus socialista» $(634)^{21}$.

\section{EL SOCIALISMO BELGA EN POR LA EUROPA CATÓLICA}

Y así queda preparado el terreno para la visita a Gante, ciudad llamada «relámpago rojo» (634) por la autora. Llevaba cartas de presentación para varios socialistas que le había proporcionado Giner de los Ríos pero no encontró a ninguno: los «socialistas intelectuales» que quería encontrar estaban de vacaciones $(635)^{22}$. El adjetivo apunta a la composición heterogénea del

20 «Il n'est pas douteux que ces Boerenbonden aient puissamment contribué à répandre les principes coopératifs parmi les paysans. Au lieu des procédés techniques défectueux que l'on employait, jusque dans ces dernières années, pour la fabrication du beurre, on recourt aujourd'hui à des modes de production qui vont toujours en se perfectionnant». (Destrée y Vandervelde, 1898: 327)

${ }^{21}$ «Nous savons bien que, dans la pensée de leurs promoteurs, les corporations chrétiennes s'arrêtent à mi-chemin; qu'elles repoussent tous ceux qui ne font pas adhésion formelle au principe de la propriété privée; qu'elles essaient d'adapter au milieu moderne les formes médiévales de la production; qu'elles n'ont, au fond, d'autre but que de faire la part du feu, de vacciner les paysans contre le socialisme, en leur inoculant un peu du virus socialiste». (Destrée y Vandervelde, 1898: 442)

${ }^{22}$ Al regresar de su viaje, escribe a Giner el 1 de septiembre de 1901: «De sus cartas de usted ninguna pude entregar personalmente. Los dos señores de Bruselas y el de Gante encontrábanse en viaje, aprovechando las vacaciones» (Varela, 2001: 490). En esta carta y 
partido socialista en cuya cumbre se encontraban miembros emanados de la burguesía, como Émile Vandervelde, catedrático de la Universidad Libre de Bruselas, y Jules Destrée, doctor en derecho, y otros como Edward Anseele, emanado de un medio artesanal, dos vertientes que tardaron en encontrarse ${ }^{23}$ pero que en 1900 ya operaron de consuno. El que Emilia Pardo Bazán se propusiera entrevistar a unos hombres políticos que defendían puntos de vista diametralmente opuestos a los suyos habla a favor de su seriedad como periodista. Es una lástima que no lo consiguiera, porque estas voces habrían constituido un contrapeso a las autoridades católicas que dominan los dos tercios de los capítulos ideológicos de su libro.

Las múltiples referencias al libro de Destrée y Vandervelde suplen de alguna manera las entrevistas que no pudieron tener lugar. Como en Lovaina la autora visitó las dependencias de la 'Gilde' y de la Liga de los campesinos, en Gante se dirige a 'Vooruit' (lit. 'Adelante'), la cooperativa colectivista. La autora describe su visita al edificio que comprende unos almacenes «-en humilde y barato- reproducción de los grandes Almacenes de París» (635), la caja de ahorros y el banco. Basándose en los datos de Le socialisme en Belgique, describe la importancia de Gante como cuna del socialismo belga (Destrée y Vandervelde, 1898: 12-13 y 15) y hace una digresión acerca del sufragio universal (134), lo que le permite otra comparación con España. Allí el sufragio universal existe, pero el caciquismo impide que produzca el efecto que debería:

Fijémonos bien: el sufragio universal, que aquí se nos cayó en la boca, verde y duro, una mañana, y nos era tan imprescindible que lo trasformamos en el encasillado; el sufragio universal, digo, esa libertad escrita, especie de doña Blanca de Navarra, que se pudre en la sombría torre de Gobernación sin que su esposo, el pueblo, se acuerde de visitarla nunca [...]. (Pardo Bazán, 2006b: 636).

A continuación, la autora va describiendo las etapas ya cumplidas en dirección al sufragio universal. Su observación de que «[...] los católicos, en vez de alejar sistemáticamente a los socialistas del Parlamento, les abrieron la puerta» (637) mediante el voto plural es conforme a la verdad pero habría sido más exacto atribuir la iniciativa, que causó una fuerte división en el seno del partido católico, al ala moderada que se dio cuenta de que la base electoral se había hecho demasiado estrecha (Deneckere, 2005: 536 y Mabille, 1986: 192).

en la que le escribe el 9 de septiembre, aparecen dos nombres de personas para las que llevaba cartas de Giner: Guillaume Tiberghien, catedrático de filosofía de la Universidad de Bruselas, krausista, amigo personal de Giner y miembro del partido liberal, que había fallecido poco antes, y Eugène Van der Rest, otro catedrático de filosofía (Varela, 2001: 496).

${ }^{23}$ «Le socialisme théorique, né de la pitié, restait séparé du socialisme pratique, né de la souffrance, par toute l'épaisseur des couches sociales intermédiaires. Il fallut encore de longues années, semées de dures épreuves, pour que les penseurs et les prolétaires se rejoignissent et se donnassent la main». (Destrée y Vandervelde, 1898: 14) 
.La autora menciona el suicidio de Albert Nyssens, el ministro que había elaborado la fórmula del voto plural, compromiso entre el sufragio universal y el voto censitario, el 20 de agosto de 1901, cuando ella estaba en Bruselas. En este capítulo, la autora intuye que la tranquilidad que respira en Bélgica es superficial. Declara:

Una impresión extraña me acompañó durante mi viaje belga, y voy a apuntarla aquí. Sin duda por la tendencia del artista a transformar las ideas en imágenes sensibles, a aquel país superficialmente tan pacífico lo veía en guerra; en cuanto me rodeaba parecíame olfatear y respirar la lucha [...]. (Pardo Bazán, 2006b: 637).

Pero en el párrafo siguiente se retracta: considera que los choques frontales entre los socialistas en huelga y las fuerzas del orden pertenecen al pasado: «Hoy podrán ocurrir colisiones, represiones exageradas, pero ya no son sistema, o son sistema desacreditado»; sin embargo, al revisar sus artículos para la publicación en libro, se ve obligada a añadir una nota: «A la hora en que esto escribo ha vuelto a encenderse la lucha» (638), aludiendo a las tensiones que llevaron a una nueva huelga general en febrero de 1902, relacionada una vez más con la lucha por el sufragio universal (Deneckere, 2005: 551 y Mabille, 1986: 196-197).

Siguen unos párrafos relacionados con la fuerza de las cooperativas socialistas, basadas una vez más en Destrée y Vandervelde (1898: 45 y 49) pero resulta curioso el enfoque: «Contra la inmensa mutualidad católica, los colectivistas han hecho prodigios» (Pardo Bazán, 2006b: 638), cuando en realidad las primeras iniciativas fueron socialistas y las católicas se produjeron como reacción a las primeras. La cooperativa de 'Vooruit' se fundó en 1880, cinco años antes de la 'Gilde'. La autora destaca con razón que la base del éxito político de los socialistas se encuentra en la fuerza económica de las cooperativas.

De allí pasa a la forma de gobierno. Destaca que tanto entre los católicos como entre los socialistas abunda la crítica a la figura del monarca, Leopoldo II, cuyo comportamiento licencioso es juzgado con severidad por sus compatriotas. Observa que no había unanimidad en el mundo político para aceptar el legado que quería dejar el rey a Bélgica, el Congo, del que Leopoldo era rey absoluto, siendo los socialistas los que con más energía se oponían a este proyecto. El tema era de actualidad puesto que en mayo de 1901, cuando el primer ministro Beernaert, católico, había propuesto que Bélgica retomara el Congo inmediatamente, el rey no quiso, probablemente porque quería sacar más provecho personal de la prosperidad congoleña y como los liberales y los socialistas también se opusieron en el parlamento, el primer ministro tuvo que retirar su propuesta (Ndaywel è Nziem, 1998: 358). El asunto quedaría arreglado en 1908, cuando el parlamento aprobó la ley de anexión del Congo (Dumont, 1977: 440).

Las reflexiones de doña Emilia acerca del tratamiento de la cuestión social en Bélgica se prolongan en el artículo titulado «El descanso dominical». En él elabora la frase que concluye el artículo anterior: «[...] aquí rige una 
ley singularísima: los adversarios suelen querer 'lo mismo' aunque no 'para lo mismo'» (Pardo Bazán, 2006b: 638). Entra en el tema del descanso dominical por la vía de los sellos de correo provistos de un letrerito que reza «no entregar en domingo» que se puede arrancar, lo cual le parece un invento interesante para facilitar la tarea de los carteros el domingo y propone su introducción en España. La versión de su texto publicada en libro contiene una nota: en febrero de 1902 la Liga española para el fomento del descanso dominical le informa de una iniciativa similar (642). La despiadada industrialización, primero de Inglaterra, luego del continente europeo, había acabado con la secular norma cristiana de descansar el domingo; la recuperación del descanso dominical y de un horario comercial limitado era una conquista socialista, como reconoce la autora. Si tanto los socialistas como los católicos reivindican 'lo mismo', no es 'para lo mismo': «[...] los socialistas belgas, de cuya campaña forma parte tan integrante el reposo dominical, aspiran, no diré a 'santificar', sino a 'humanificar' el domingo» (641). La autora da ejemplos de ambas interpretaciones. Los católicos se dedican a las obras: las visitas del domingo a niños pobres en los hospitales, los círculos en los que se entretiene y enseña a niños y jóvenes. En su descripción enfatiza la dimensión caritativa de estas obras «que por cima del socorro material buscan la reconciliación de las clases, el abrazo de las almas» (641). Los socialistas humanizan el domingo «dedicándolo a distracciones y goces más humanos que bestiales» (641). La autora cita la actividad de propaganda contra la ginebra, el juego y el carnaval entre los socialistas belgas y en este punto su actuación concuerda con la católica ${ }^{24}$. La conclusión que saca de sus observaciones es utópica:

[...] he creído ver el suelo belga rayado por dos surcos, uno rojo, otro azul, que parten de la frontera desde extremos opuestos, y, sinuosos, pareciendo que se desvían, llegan por fin a juntarse. La dirección de ambos surcos converge fatalmente. Son el catolicismo social y el socialismo. Van derechos a la entraña y en el calor de sus pliegues habrán de reunirse. (641).

La unión no podía producirse debido a que el catolicismo social defendido por la autora apoyaba las iniciativas privadas para hacer más llevadera la vida de los obreros, mientras que el socialismo reivindicaba para ellos más derechos por la vía institucional.

\section{CONCLUSIÓN}

La autora se propuso informarse e informar a sus lectores españoles sobre el catolicismo social belga y lo hizo entrevistando a unas figuras selectas

\footnotetext{
${ }^{24}$ Aquí una vez más el libro de Destrée y Vandervelde (1898: 248-251) puede haber sido la fuente de referencia.
} 
y visitando instituciones relevantes. Es cierto que en poco tiempo hizo bastante, aunque ella misma se dio cuenta de las prisas con las que tuvo que trabajar. En una carta del 9 de septiembre de 1901 dirigida a Giner de los Ríos escribe: «He andado algo aprisa en mi información, aunque creo haber aprendido bastante, gracias a mi asimilación rápida» (Varela, 2001: 496). Es indudable que el obispo de Lieja, Doutreloux, y la Gilde de Lovaina desempeñaron un papel de primera importancia en la evolución hacia un catolicismo más comprometido con la suerte de los desheredados. Pero en el 1901 ya se estaba destacando dentro del catolicismo social un movimiento menos paternalista y el inicio de un auténtico sindicalismo cristiano autónomo y en este sentido es una lástima que la autora no haya hablado con Arthur Verhaegen o alguno de sus partidarios representativos de la incipiente democracia cristiana. La entrevista con Mercier es importante porque demuestra la compatibilidad entre el catolicismo y la ciencia moderna, aunque el lector español no aprende nada sobre las dificultades que tuvo que superar el presidente del Instituto Superior de Filosofía en sus inicios. Doña Emilia se propuso entrar en contacto con algunos prohombres socialistas pero no lo consiguió y la perspectiva socialista la tiene que sacar de una fuente libresca, Le socialisme en Belgique de Destrée y Vandervelde. El que lo intentara, a pesar de su franca aversión del socialismo, habla a favor de su seriedad de periodista ${ }^{25}$.

La autora tiende a minimizar las fisuras dentro del bloque católico y a exagerar las convergencias entre católicos y socialistas. Resulta sorprendente, además, que no mencione en ningún momento la tercera gran fuerza política del país, de un poder al menos equivalente al del socialismo, el liberalismo. El lector español que no tuviera más información sobre la Bélgica de su tiempo que Por la Europa católica podría llegar a pensar que solo había un partido católico y otro socialista. Este lector tendría además la impresión de que la conflictividad político-social se reducía a disensiones ideológicas entre señores cultos que respetaban altamente a sus adversarios; es evidente que podemos tomar en serio la incitación de los benedictinos de la abadía de Maredsous, otro centro intelectual de pro, a que Pardo Bazán se entreviste con todos, pero esto no quiere decir que la tónica general fuera de tolerancia. A la hora en que la autora trabajaba en la publicación en volumen, a principios de 1902, se organizaba otra huelga general que no podía dejar de mencionar, de modo que ella misma tuvo que rectificar la impresión de Bélgica como una balsa de aceite que podría tener el lector.

Cabe preguntarse si la autora no se dio cuenta del clima de luchas sociales e ideológicas y de las disensiones en el seno del partido católico, debido

${ }^{25}$ Como observa Xosé Ramón Barreiro Fernández, «Doña Emilia estaba convencida de la incapacidad del socialismo como modelo para procurar el bienestar social. Confiaba únicamente en la capacidad de los individuos como motor del desarrollo económico y social. Este individualismo procedía de la cultura liberal»(2003: 28). 
al poco tiempo que pasó en el país y además en verano, o si prefirió no hacer hincapié en ello para que el catolicismo 'moderno' belga pudiese seguir figurando de modelo para el catolicismo 'atrasado' español. Resulta que sí estaba al tanto. Escribe en una carta a Giner de los Ríos, fechada el 9 de septiembre de 1901:

Supe en Bélgica las insidias y obstáculos que se pusieron al Venerable Obispo de Lieja (que estará en el cielo) y a todos los demócratas cristianos. Al provistarse el obispado de Namur dijo un conservador católico al ministro: «No nos endosen Vds. otro Mgr. Doutreloux. Ya nos basta con uno». Pero, a los españoles, no conviene hablarles de eso, sino de lo otro, de la influencia social y obras admirables de esos católicos que no tienen contra sí el ambiente, puesto que han desbaratado las tiranías y extendido su influjo en todas las clases sociales ${ }^{26}$. (Varela 2001: 196).

Aquí, visiblemente el ideal regeneracionista pudo más que la ética periodística.

No hay que confundir el entusiasmo de la autora por las obras sociales católicas tal como se practicaban en Bélgica $^{27}$ con una evolución hacia posturas más progresistas ${ }^{28}$. Según la autora, la suerte de las clases desfavorecidas sólo podía mejorar gracias a las iniciativas desinteresadas de filántropos adinerados en estrecha cooperación con el clero, no mediante la reivindicación de derechos por parte de los desfavorecidos mismos. A este respecto podríamos decir que la autora se repliega en una ética de tipo neomedieval, paralela a su aprecio por la estética neogótica. El ideal estético y social que quiere transmitir en las páginas de Por la Europa católica se resume de modo espléndido en el siguiente párrafo, la impresión de un atardecer en Maredsous:

Anochecía casi. En una de esas praderas aterciopeladas de la tierra flamenca pastaban las vacas y los bueyes del convento, blancos con negros tachones, o color de caoba, como los que vemos en los cuadros de Pablo Potter y de Snyders. El pastor era un lego, con sombrero de anchas alas y cayado. Las campanas dulces y argentinas de la abadía tocaron el Angelus Domini. El lego se descubrió y levantó la cabeza para rezar; el sol poniente, un sol pálido, benigno, le alumbró de

\footnotetext{
${ }^{26}$ Los conservadores, apoyados por el rey Leopoldo II, consiguieron hacer nombrar como sucesor de Doutreloux en Lieja a su candidato, monseñor Rutten.

${ }^{27}$ En la carta a Giner del 1 de septiembre, escribe: «Si viviera en Bélgica creo que estaría metida de cabeza en el movimiento de obras colectivas que allí existe [...]» (Varela, 2001: 490).

${ }^{28}$ A este respecto discrepamos con Pilar Faus Sevilla cuando escribe que, pocos años más tarde, «aquellas ideas progresistas que habían surgido tras su gira por la Europa católica parecen haber desaparecido. En su lugar se ha incrementado el conservadurismo propio de la privilegiada clase social a la que pertenece y el consiguiente rechazo a las ideas de igualdad con que políticamente estaban luchando los anarquistas y socialistas. Su postura con respecto a las clases bajas, vuelve a ser la tradicional de la limosna y la beneficencia» (Faus Sevilla, 2003: 445). En nuestra lectura, lo que a la escritora la entusiasma y sigue entusiasmando en Bélgica es la eficacia y la escala de las obras sociales católicas que permitían una competencia eficaz con el socialismo.
} 
lleno la cara y las rizosas barbas de cobre. Era aquello un entrepaño de tríptico, y su fondo, minucioso y bien señalado, la cortina de vegetación que los pintores flamencos reproducen prolijamente. Un soplo de misticismo tranquilo e intenso por el aire... (Pardo Bazán, 2006b: 610).

Al libro sobre la Europa católica moderna subyace una corriente de nostalgia hacia una Edad Media idealizada.

\section{BIBLIOGRAFÍA CITADA}

Alonso, Cecilio (2007). «Literatura y prensa periódica en España en tiempos de Pardo Bazán (1866-1921)», en: José Manuel González Herrán, Cristina Patiño Eirín y Ermitas Penas Varela (eds.), Emilia Pardo Bazán: El periodismo. III Simposio, A Coruña 3, 4, 5, 6 e 7 de octubre de 2006. A Coruña: Real Academia Galega, pp. 58-67.

Aubert, Roger (1994a). «Désiré Mercier et les débuts de l'institut de Philosophie», en: JeanPierre Hendrickx, Jean Pirotte, y Luc Courtois (1994), pp. 99-115.

Aubert, Roger (1994b). «Le cardinal Mercier et Mgr. Rutten», en: Jean-Pierre Hendrickx, Jean Pirotte y Luc Courtois (1994), pp. 175-185.

Barreiro Fernández, Xosé Ramón (2003). «Emilia Pardo Bazán en su tiempo histórico», en: Ana María Freire López (ed.), Estudios sobre la obra de Emilia Pardo Bazán. Actas de las Jornadas conmemorativas de los 150 años de su nacimiento. A Coruña: Fundación Pedro Barrié de la Maza, pp. 15-30.

Carta encíclica Rerum novarum del Sumo Pontífice León XIII sobre la situación de los obreros (1891), [http://www.vatican.va/holy_father/leo_xiii/encyclicals/documents/hf_lxiii_enc_15051891_rerum-novarum_sp.html, consultado el 10.08.2010].

Courtois, Luc (1994). «Le cardinal Mercier: introduction à l'étude d'une personnalité», en: Jean-Pierre Hendrickx, Jean Pirotte y Luc Courtois (1994), pp. 79-97.

De Maeyer, Jan (1994). De rode baron. Arthur Verhaegen. 1847-1917. Lovaina: Universitaire Pers Leuven.

De Maeyer, Jan y Leen Van Molle (1998). Joris Helleputte. Architect en politicus. 18521925. Deel 1 Biografie. Lovaina: Universitaire Pers Leuven.

Deneckere, Gita (2005). «Nieuwe geschiedenis van België 1878-1905», en: Els Witte, JeanPierre Nandrin, Eliane Gubin y Gita Deneckere, Nieuwe geschiedenis van België I (18301905). Tielt: Lannoo, pp. 447-664.

Destrée, Jules y Émile Vandervelde (1898). Le socialisme en Belgique. Paris: V. Giard \& E. Brière.

Doutreloux, Victor-Joseph (1894). Lettre pastorale de Sa Grandeur Mgr. Doutreloux, évêque de Liège au clergé de son diocèse sur la question ouvrière, suivi de l'encyclique «Rerum novarum» et de plusieurs documents pontificaux. Liège: Dessain.

Dumont, Georges-H. (1977). Histoire de la Belgique. Paris: Hachette.

Faus Sevilla, Pilar (2003). Emilia Pardo Bazán. Su época, su vida, su obra. A Coruña: Fundación Pedro Barrié de la Maza.

Freire López, Ana María (1999). «Los libros de viajes de Emilia Pardo Bazán: el hallazgo del género en la crónica periodística», en: García Castañeda (1999), pp. 203-212.

Freire López, Ana María (2005). «Emilia Pardo Bazán: Periodismo y Literatura en la prensa», en: J.M. González Herrán, et al. (eds.), Emilia Pardo Bazán. Estado de la Cuestión. Simposio A Coruña, 2, 3 e 4 de xuño de 2004. A Coruña: Real Academia Galega, pp. 19-31.

García Castañeda, Salvador (coord.) (1999). Literatura de viajes. El viejo Mundo y el Nuevo. Madrid: Castalia. 
Gérin, Paul (1978). «Le fonds Doutreloux», en: A. Deblon, P. Gerin y L. Pluymers (eds.), Les archives diocésaines de Liège. Inventaires des fonds modernes. Lovaina: Nauwelaerts, 1978, 92-100.

Gilde der Ambachten en Neeringen van Loven. Ambacht der Houtbewerkers. s.d., s.l.

González Herrán, José Manuel (1999). «Un inédito de Emilia Pardo Bazán: Apuntes de un viaje. De España a Ginebra (1873)», en: García Castañeda (1999), pp. 177-187.

González Herrán, José Manuel (2000). «Andanzas e visións de doña Emilia (A literatura de viaxes de Pardo Bazán) », Revista Galega do Ensino, 27, pp. 37-62 [en línea, http:// dialnet.unirioja.es/servlet/articulo?codigo=1368849, consultado el 23.08.2010].

Hendrickx, Jean-Pierre, Jean Pirotte y Luc Courtois (eds.) (1994). Le cardinal Mercier (18511926). Un prélat d'avant-garde. Publications du professeur Roger Aubert rassemblées à l'occasion de ses 80 ans. Lovaina: Presses Universitaires de Louvain.

Jiménez Morales, María Isabel (2008). «Emilia Pardo Bazán, cronista en París (1889)», Revista de Literatura, LXX, 140, pp. 507-532.

Mabille, Xavier (1986). Histoire politique de la Belgique. Facteurs et acteurs de changement. Bruxelles: Centre de recherche et d'information socio-politiques.

Montero, Feliciano (1997). «Conservadores e liberales ante la 'cuestión social': el giro intervencionista», Revista de filología románica, 14, 2, pp. 493-504.

Montero, Feliciano (2004). «El catolicismo social en España. Balance historiográfico», en: Benoît Pellistrandi (ed.), L'histoire religieuse en France et en Espagne. Madrid: Casa de Velásquez, pp. 389-409.

Ndaywel è Nziem, Isidore (1998). Histoire générale du Congo. De l’héritage ancien à la République Démocratique. Bruxelles: Duculot \& Afrique-Éditions.

Pardo Bazán, Emilia (2006a). Cuarenta días en la Exposición, en: Viajes por Europa. Introducción y Cronología de Tonina Paba. Madrid: Bercimuel, pp. 441-586.

Pardo Bazán, Emilia (2006b). Por la Europa católica, en: Viajes por Europa, pp. 587-667.

Revuelta González, Manuel (2000). «Creencias», en: Manuel Espadas Burgos, (coord.), La época de la Restauración (1875-1902). Volumen II. Civilización y cultura. Madrid: Espasa-Calpe, pp. 50-121.

Schmitz, Philibert (1962). «Hemptinne, Félix de, en religion dom Hildebrand», Biographie nationale, 31, suplemento 3, pp. 445-451.

Simon, A. (1959). «Doutreloux», Biographie Nationale, 30, suplemento 2, p. 347.

Simón Palmer, Carmen (2008). «Correspondencia de Antonio Maura con Emilia Pardo Bazán, Sofía Casanova y Concha Espina», Revista de Literatura, LXX, 140, pp. 625-652.

Sotelo, Marisa (2005). «Aproximación al pensamiento político de Emilia Pardo Bazán», en: Virginia Trueba et al. (eds.), Lectora, Heroína, Autora (La mujer en la literatura española del siglo XIX). III Coloquio de la Sociedad de Literatura Española del Siglo XIX (Barcelona, 23-25 de octubre de 2002). Barcelona: Universitat de Barcelona PPU, pp. 357-367.

Varela, José Luis (2001). «E. Pardo Bazán: Epistolario a Giner de los Ríos. (Continuación)», Boletín de la Real Academia de la Historia, 198, pp. 439-506.

Fecha de recepción: 14 de septiembre de 2010

Fecha de aceptación: 14 de abril de 2011 